\title{
Problemas públicos, casos resonantes y escándalos. Algunos elementos para una discusión teórica*
}

\author{
Carolina Schillagi \\ Universidad Nacional de General Sarmiento, Buenos Aires, Argentina. \\ Email: cschilla@ungs.edu.ar
}

\begin{abstract}
Resumen: ¿Cuál es la relación que se conforma en determinados momentos históricos entre ciertos acontecimientos, transformados en casos resonantes o escándalos políticos, y un problema público? ¿Qué permite entrever el estudio de los "casos" respecto de un aspecto o un momento en la conformación de ese problema público como tal? Estas son algunas de las cuestiones que vamos a examinar en este artículo, invitando a reflexionar acerca de la relación entre diversas perspectivas teóricas y entramados conceptuales provenientes tanto del campo de estudio de la sociología de los problemas públicos, como de las teorías del escándalo y del acontecimiento.
\end{abstract}

Palabras clave: Problemas públicos, escándalos, acontecimiento, movilizaciones sociales

\section{Public problems, notorious cases and scandals. Some elements for a theoretical discussion}

\begin{abstract}
Which is the relationship that is produced in specific historical moments between certain events, changed into notorious cases or political scandals, and a public problem? What can the study of the cases suggest in regarding an aspect or a moment in the shaping of that public problem as such? These are some of the matters that are going to be examined in this article, inviting us to think on the relationship between different theoretical perspectives and conceptual frameworks steaming from the field of study of the sociology of public problems, as well as of scandal and event theories.
\end{abstract}

Key words: Public problems, scandals, events, social demonstrations

\section{Problemas públicos, casos notórios e escândalos. Alguns elementos para uma discussão teórica}

Resumo: Qual é a relação que é produzida em momentos históricos específicos entre certos acontecimentos transformados em casos notórios ou escândalos políticos, e um problema público? O que pode o estudo dos casos sugerem sobre um aspecto ou um momento na formação desse problema público como tal? Estes são alguns dos assuntos que vão ser examinadas neste artigo, convidando-nos a reflectir sobre a relação entre as diferentes perspectivas teóricas e marcos conceituais de ambos desde o campo de estudo da sociologia do público problemas, como da teoria dos escândalos e eventos. 

sociais.

Palavras-chave: problemas publicos, escândalos, eventos, demonstrações

\section{Los acontecimientos y los “casos” como parte de la constitución de un problema público}

El campo de estudio de los problemas públicos se asienta en una visión constructivista de la realidad social y a partir del pionero trabajo de H. Blumer (1971), sostiene que los problemas sociales son el resultado de un proceso de definición colectiva por el que ciertos acontecimientos o "hechos" son así considerados por determinados actores sociales y no el reflejo de condiciones objetivas pre-existentes. A partir de estudios posteriores, es la consideración de los problemas sociales como actividades llevadas adelante por individuos o grupos sobre alguna situación supuesta o posible (putative conditions), la definición más difundida en el campo de estudio al que nos estamos refiriendo (Spector y Kitsuse, 1977).El objeto de la sociología de los problemas sociales es entonces ese proceso por el cual los miembros de grupos o de sociedades definen a una "condición supuesta”, como un problema.

Avanzando aún más en la ampliación de este campo de estudio, Gusfield (1981) se interroga acerca del carácter público de los problemas sociales. Ya no se trata sólo de una competencia entre definiciones postuladas sobre algo que es concebido como problema, sino que la naturaleza pública de ese problema también está abierta a diversas maneras de concebir su solución o resolución (Ibid, 1981: 5). Esas vías de resolución de un problema (“quién hará algo al respecto”) se ponen en juego públicamente y plantean la necesidad de atender a la cuestión de la responsabilidad, como una dimensión que entraña aspectos culturales y estructurales, en tanto niveles que han de ser incluidos en el análisis ${ }^{1}$.

Para que un problema exista, entonces, debe ser reconocido como tal por algunos actores, que se movilizarán para demostrarlo y que buscarán contar con la mayor cantidad de apoyos posibles para hacer prevalecer públicamente sus demandas. Sin embargo, esto no es lo único que debe suceder, dado que otros problemas así definidos por otros actores, también pugnarán por ese mismo reconocimiento y por otra parte, distintas definiciones al interior de un mismo problema harán lo propio. El reconocimiento de la existencia de un problema entre muchos otros o de determinada definición entre otras posibles del mismo problema, plantea entonces la cuestión de las arenas en las que ese problema se desarrolla y de cómo opera un proceso de selección como principio operativo de las mismas. La idea de "arena pública” puede verse como un espacio conflictivo en el que emergen los problemas y donde se desarrolla una compulsa entre actores de fuerza desigual para imponer sus definiciones o conducir acciones respecto del mismo ${ }^{2}$. 
Estas actividades que motorizarán determinados grupos para hacer prevalecer una definición o un problema entre otros, buscan, al mismo tiempo, lograr la adhesión o al menos la movilización emotiva de audiencias. Estas audiencias serán más amplias cuanto más operen mecanismos de generalización entre un caso particular y una situación social general o universal. Esto es, mientras más se logre vincular el problema con una temática previamente existente o familiar para la audiencia, más cerca se estará de alcanzar apoyos o una permanencia más prolongada de ese problema en la agenda y la atención públicas. Una manera de lograr esto, es tomar en consideración casos particulares, que por lo general son identificados como ejemplos de una situación no deseada y sobre la que es necesario actuar.

En este sentido, la gran mayoría de los estudios empíricos sobre problemas públicos, enfatizan en los casos (en tanto acontecimientos dotados de ciertas características específicas) así como en los escándalos, para ejemplificar o mostrar un determinado estado de cosas que contribuye a la comprensión de algunos aspectos del problema analizado (Clavérie, 1994; De Blic y Lemieux, 2005; Thireau y H. Linshan, 2005; Boltanski et. al., 2007). Es en torno a los casos o los escándalos, que se despliega y se vuelve públicamente más visible todo ese conjunto de prácticas y categorizaciones, narraciones y relatos que forman la base de sustentación práctica y simbólica de un problema público. De todos modos, la vinculación que se avizora entre los acontecimientos devenidos escándalos o casos y un problema o una cuestión mayor que los configura y a la que contribuyen a configurar (así como el modo que adquiere la misma en determinado momento y lugar) es, en todo caso, una cuestión a ser indagada y no un supuesto de partida de la investigación. Por lo tanto, comenzaremos por examinar algunas de las visiones teóricas propuestas, con la idea de identificar ciertas dimensiones analíticas que puedan servir de guía para llevar adelante dicha tarea.

\section{La noción de acontecimiento}

El acontecimiento ha sido abordado también en conocidos estudios empíricos con un énfasis especial en el papel que juegan los medios de comunicación en su constitución como fenómeno (Verón, 1983; Champagne, 1984). Sin embargo, algunas elaboraciones teóricas sobre la noción de acontecimiento, proponen apartarse de las concepciones puramente centradas en la tarea de los medios de comunicación y agregar otros aspectos al estudio del fenómeno.

Para Néveu y Quéré (1997) existe una relación entre enfoque constructivista y problemática del acontecimiento: los eventos públicos son el resultado de actividades prácticas rutinarias y estrategias de numerosos actores sociales interesados en modelar los acontecimientos. Los autores desarrollan tres cuestiones que ayudan a precisar esa relación: la idea de construcción, la noción de acontecimiento y la constitución simbólica del mismo. 
Con relación a la idea de construcción, sostienen que no basta entonces verificar las operaciones constitutivas que realizan los medios al clasificar, categorizar, poner de relieve, describir o publicar determinados acontecimientos o "casos", sino que es preciso salir de ese campo específico y seguir al acontecimiento en su devenir como tal en otros ámbitos y arenas en los cuales actores, instituciones y prácticas se ponen en funcionamiento para contribuir a su despliegue y construcción social.

Esta preocupación por no caer en un reduccionismo que gire en torno a los medios de comunicación y su papel en la construcción del acontecimiento, es compartida con aquellas aproximaciones teóricas que abarcan el campo más amplio del estudio de los problemas públicos. Creemos que en el estudio de los acontecimientos es todavía más necesario despejar ese predominio de la dimensión enfocada exclusivamente hacia el papel de los medios, en la medida en que existe una mayor tendencia a asimilar acontecimientos con hechos noticiables.

Esto último crea un obstáculo para arribar a una comprensión más vasta de un proceso que podríamos denominar como el de "devenir acontecimiento", es decir, un proceso en el que están comprometidos una amplia diversidad de actores y prácticas (que por cierto exceden el campo de los medios de comunicación) así como bagajes culturales, políticos e ideológicos que forman parte del mismo.

Esta cuestión es señalada por Néveu y Quéré cuando se abocan a dilucidar la especificidad de la noción de acontecimiento, postulando que se trata de algo más que un hecho inesperado, singular e irrepetible. El acontecimiento implica un devenir, un fenómeno que adquiere valor e importancia desde cierto punto de vista y adviene foco de la atención pública (Ibid: 15).

Un aspecto importante en la reflexión teórica sobre la noción de acontecimiento es el de su temporalidad. El hecho de que sea sólo retrospectivamente que podamos hablar de acontecimiento, no es algo menor. Incluso podría postularse que esta relación entre acontecimiento y tiempo, es donde más claramente se deja ver el carácter procesual de la construcción propiamente dicha del mismo. Es sólo luego de transcurrido, que puede calibrarse su peso histórico o su intrascendencia relativa, que se ha seleccionado un modo de describirlo entre muchos otros, que se lo ha catalogado y hecho público siguiendo determinadas operaciones narrativas o retóricas, etc.

Llegamos así a la tercera cuestión señalada por los autores franceses: la constitución simbólica del acontecimiento. En ella intervienen dos dimensiones interrelacionadas: la reducción de la indeterminación y la atribución de determinado valor o significación al acontecimiento.

Existen ciertas estructuras formales de esta constitución simbólica de los acontecimientos, que conciernen esencialmente a los procesos de 
individuación social de los mismos en determinada sociedad y comprenden cierta concepción del tiempo, algún tipo de conciencia histórica, un modo de temporalizar la esfera social, determinada estructura temporal de la experiencia individual y colectiva En la investigación será entonces necesario tener en cuenta estas dimensiones, atendiendo al modo en que operan determinadas limitaciones planteadas por las organizaciones mediáticas, pero también por las descripciones orientadas y delimitadas por el valor semántico de los términos utilizados en ellas (Ibid: 18).

Si la constitución simbólica del acontecimiento está socialmente organizada, ello indica que hay otras dimensiones de los procesos sociales que tienen su peso en ella. Por una parte, lo que algunos autores llaman la estabilización o fijación del significado, es decir, las condiciones bajo las cuales ciertas instituciones disponen de un poder para contar la verdad pero también las contra-estrategias a través de las cuales otras instituciones o grupos buscan deslegitimar estas narraciones autorizadas. Y, por otra parte, la necesidad de no concebir la selección e interpretación como el resultado de un proceso estratégicamente controlado o controlable, dado que incluso actores con amplios y poderosos recursos tienen dificultades para garantizar el control real de la recepción de una política pública (Ibid: 22).

Es esta idea de la recepción la que juega un papel central en la aproximación conceptual de otro autor, Michel Barthélémy (1992), que ha trabajado la noción de acontecimiento. Desde su perspectiva, es la problematización de la relación entre: a) acontecimiento y descripción y b) acontecimiento y acción pública, lo que hace posible tomar distancia respecto de una concepción del mismo exclusivamente centrada en el papel de los medios.

La tesis de Barthélémy (1992) es que la recepción de los acontecimientos es un componente intrínseco de su individuación social y no un fenómeno contingente vinculado al rol preponderante de los medios. Es decir que la recepción pública de un acontecimiento consiste en operaciones y prácticas que ayudan a que el problema identificado sea considerado aceptable o manejable desde un punto de vista social (Ibid). Esa aceptación social implícita, implica tanto el despliegue de una descripción del acontecimiento bajo determinado contexto elaborado por la acción colectiva, cuanto un proceso de "normalización” o estabilización compuesto por operaciones que acuden a reducir su contingencia y unas determinadas formas de implicación del público.

Existe una interrelación entre esa movilización de un público y la descripción del acontecimiento, que no proviene de una asimilación directa de lo ocurrido sino de un proceso por el cual, lo que es descripto de determinada manera ayuda a delimitar el problema planteado a la comunidad. Por eso también puede hablarse de una dialéctica entre descripción y acción pública, puesto que ese modo de describir está marcando, a su vez, a quién incumbe lo sucedido y qué ha de hacerse al respecto ${ }^{3}$. 
La conformación de una movilización pública, es, pues, un aspecto crucial en el estudio de los acontecimientos. En este punto resulta importante reparar en una cuestión en particular: la relación entre acontecimiento y constitución de un público puede ser articulada a través del concepto de experiencia (França y Almeida, 2008).

La idea de que el acontecimiento pertenece al orden de los hechos pero se constituye en el campo de la experiencia, reenvía a una concepción según la cual no se trata sólo de una configuración de sentido de naturaleza discursiva o narrativa, sino que hay una faceta disruptiva en el acontecimiento, que produce novedad al introducir un corte en la normalidad de las cosas, operando transformaciones sobre el mundo y sobre aquellos que lo experimentan. Para Quéré, hechos y acontecimientos no constituyen dos entidades distintas y tampoco sería adecuado definir al acontecimiento promoviendo una dicotomía entre hecho y sentido. Si los acontecimientos son, efectivamente, hechos de la realidad, su definición debe buscarse más bien en el poder de afectar que estos conllevan. Es decir que es en el campo de la experiencia que los acontecimientos se constituyen como tales (Ibid).

Tener en cuenta esta dimensión de la experiencia en el estudio de los acontecimientos, constituye una herramienta de lo más fructífera para dar cuenta de los mismos en toda su complejidad. Esta complejidad implica examinar lo que la noción de experiencia tiene de acción pública, de acción de un público constituido en y por el acontecimiento.

Además de ser un fenómeno revelador, el acontecimiento crea condiciones renovadas para interpretar la realidad circundante y el campo problemático en el cual toma forma. Es en ese sentido que podría considerarse como portador de un poder hermenéutico (Ibid: 5). El acontecimiento es transformador en cuanto a sus implicancias y consecuencias y convoca a asumir posiciones a un amplio conjunto de actores e instituciones en tanto públicos que actúan dentro de un proceso de agenciamiento como tales. Ese proceso de agenciamiento de los públicos, encuentra en los escándalos otra de sus fuentes.

\section{La noción de escándalo}

Thompson (2001; 2005) se ha ocupado de conceptualizar la noción de escándalo en varios de sus análisis, proponiendo una definición general según la cual "escándalo denota aquellas acciones o acontecimientos que implican ciertos tipos de transgresión que son puestos en conocimiento de terceros y que resultan lo suficientemente serios como para provocar una respuesta pública” (Ibid:32, destacado en el original). Así, el escándalo supone ante todo un acontecimiento que provoca una desaprobación visible de parte de un público. No es suficiente que haya público que desaprueba, es necesario que su desaprobación sea expresada públicamente. Es la respuesta del público lo que marca, pues, la existencia del escándalo ${ }^{4}$. 
Desde la perspectiva del autor, la visibilidad mediática tiene un papel decisivo en la definición del fenómeno. Es así que la proliferación de los escándalos que ocurren en la esfera política durante los años ochenta y noventa del siglo XX, está relacionada con la emergencia de una "nueva visibilidad" (en calidad y extensión) y no con una declinación en los estándares morales de los hombres públicos o, como señalan Markovits y Silverstein a una "violación del procedimiento debido" en las democracias liberales (Thompson, 2001).

Por su parte, De Blic y Lemieux (2005) postulan la consideración plena de los escándalos como objeto de estudio y establecen algunas dimensiones que apuntan a definir el fenómeno.

En primer lugar, un escándalo consistiría en la denuncia pública de una contradicción o una controversia. El componente controversial está ligado a la transgresión de una norma que no es indiferente a una gran parte de los grupos sociales, pero el único modo de conocer la significación de esa falta cometida, es seguir a los actores en sus modos de denunciarla públicamente y en las variadas reacciones que esa acción pública suscita en otros actores (De Blic y Lemieux, 2005).

En segundo lugar, los autores señalan que un escándalo conlleva un "momento instituyente" ${ }^{5}$ que, antes que poner al descubierto ciertos aspectos de lo ya existente, lleva a plantear la pregunta por lo que éste provoca, qué cambia en las relaciones sociales, qué transforma de las maneras de actuar, los funcionamientos institucionales, las categorías para definir problemas, entre otros aspectos (Ibid). En cada uno de los casos que pueden ser estudiados, ese momento transformador que es parte del acontecimiento escandaloso y de su constitución como tal, se pone de manifiesto en los modos en que las prácticas, las rutinas, las narraciones y las representaciones sobre determinadas temáticas se ven alteradas, modificadas o reforzadas en las distintas arenas en las que el problema juega sus múltiples definiciones y en las que los actores y los públicos se constituyen ${ }^{6}$.

Este aspecto que integra la aproximación teórica que estamos revisando, resulta fundamental para visualizar cómo se puede estudiar la relación entre los acontecimientos escandalosos y los problemas públicos. El significado del escándalo no puede aprehenderse sino estudiando las reacciones que suscita el acto de denuncia pública que éste implica. Son esas reacciones las que resultan indisociables de la "gravedad de la transgresión" ocurrida; es decir que no es posible tener una medida "objetiva" de la gravedad del escándalo sin seguir a los actores que expresan públicamente su indignación o por el contrario, que buscan relativizar u ocultar lo sucedido. En ese camino, un público se constituye y es ello lo que permite ubicar el análisis de un escándalo en un cruce fructífero con el estudio de problemas públicos, pues abre la posibilidad de examinar una parte de ese proceso de constitución de un público ${ }^{7}$.

Al desarrollarse la escena del escándalo, se ponen de manifiesto las 
denuncias, los argumentos y contra-argumentos sobre lo sucedido, se movilizan estrategias y alianzas entre diferentes actores, se concita la atención de la prensa y la opinión pública. Todo este escenario obliga a los actores a tomar posiciones, a volver explícito un conjunto de relatos sobre la coyuntura en la que el escándalo se está desenvolviendo, a exponer una serie de explicaciones sobre sus prácticas, entre otras actividades que contribuyen a otorgar una cierta estabilidad al problema en cuestión, en la medida en que algunas definiciones tenderán a predominar por sobre otras posibles. Considerando este aspecto de los escándalos, se vuelve posible advertir que éstos pueden intervenir en el proceso de estabilización de un problema público, siendo tarea del analista indagar en qué medida y a través de qué mecanismos ocurre este proceso en cada caso.

En tercer lugar, De Blic y Lemieux (2005) postulan que los escándalos constituyen una suerte de de "prueba" sobre la vigencia u obsolescencia de valores morales transgredidos, permitiendo entonces conocer si la denuncia que está en la base de la constitución de todo problema público tiene un relativo sustento como tal ${ }^{8}$.

Finalmente, una dimensión importante en el estudio de los escándalos está conformada por las estrategias que desarrollan los distintos actores involucrados en la denuncia pública. Junto a las estrategias de disimulo, de conservación y de control institucional se encuentran aquellas de develamiento, de subversión o de provocación, es decir, de movilización de un público y de involucramiento de fuerzas exteriores a las instituciones puestas en cuestión. Esta dimensión estratégica de los escándalos, enfocada en las acciones que son necesarias para la "puesta en visibilidad” de los mismos, permiten estudiar una de las formas de acción más eficaces en las sociedades contemporáneas para hacer existir un problema público. Esto ocurre sobre todo, cuando los grupos involucrados no pueden dotarse de una representación estable, cuando no tienen los recursos materiales o simbólicos para hacerlo o cuando las temáticas que están en juego son poco conocidas, difusas o con débil representación en la discusión pública (Ibid).

Sin embargo, el estudio de las estrategias, si bien permite tener una medida de las desiguales relaciones de fuerza que se juegan en los escándalos, conlleva el riesgo de enfocarse exclusivamente en la actividad de los denunciados y los que buscan relativizar, deslegitimar u ocultar esas denuncias, es decir, en esa suerte de interacción estratégica entre unos y otros. Si bien ese trabajo que realizan los actores es central en el estudio de los escándalos, una aproximación tal podría subestimar el hecho de que un individuo jamás puede imponer a otros el significado de una norma o de su transgresión (Ibid).

Como recaudo metodológico, es necesario tener en cuenta dos cuestiones. Por un lado, que la presencia de los distintos sectores sociales implicados en un escándalo, con sus lógicas específicas de funcionamiento, constituyen una característica inherente a las sociedades contemporáneas. Esto permitirá además, alejarnos de una visión únicamente centrada en el 
papel de los medios de comunicación de masas en hacer existir un escándalo, para verlos como agentes de un sector social entre otros que también participan. Por otro lado, que "el evento escandaloso se juega siempre en múltiples escenarios caracterizados por grados o niveles de publicidad muy variables” y si bien existe una faceta más visible del escándalo, éste se despliega a la vez en "otros teatros de interacción entre los actores implicados”, algo que es necesario incluir en el análisis (Ibid, 2005: 27, traducción propia) ${ }^{9}$.

\section{Carácter público, politización y estabilización de un problema público}

Teniendo en cuenta las consideraciones teóricas antes expuestas, nos abocaremos ahora a examinar un conjunto de dimensiones analíticas que, si bien las incluyen, no siguen estrictamente las fases propuestas en los abordajes teóricos ligados al estudio de problemas públicos. Nos referimos en primer lugar, a la cuestión del proceso de adquisición del carácter público de un problema social. Indagaremos también, la aproximación teórica que da cuenta del proceso de "politización" del problema, aspecto que en el enfoque de los problemas públicos se identifica con la estabilización alcanzada por cierto relato de ese problema, pero que además involucra todo un campo de prácticas sociales relacionadas con demandas, reclamos, medidas de política pública, producción de legislación y debate político.

A esta altura resulta evidente que uno de los rasgos principales que caracterizan la conformación de casos y de escándalos en el escenario social, es el proceso que media entre su mera ocurrencia y su problematización pública. En efecto, el sentido común tiende a otorgar un carácter automático al pasaje entre el hecho y su tematización, muchas veces en consonancia con ciertas características dramáticas o excepcionales que parecen volver a esos hechos merecedores de "aparecer" en la escena pública o de ser conocidos por la opinión pública, sobre todo de la mano de los medios de comunicación, en tanto hechos dotados de "noticiabilidad". Sin embargo, el proceso de configuración de su carácter público no es reductible al proceso de "hacerse visible" ni sinónimo exclusivo de ello, así como tampoco hay nada de natural en el hecho que ciertas cuestiones sean consideradas dignas de ser públicamente atendidas.

Esto marca que es necesario emprender un análisis crítico de los casos sobre los que ha de trabajar el investigador. Hay que preguntarse cómo explicar e interpretar la tematización propuesta por los mismos e interrogar qué factores fueron los que habilitaron ese pasaje desde una situación particular, a su problematización pública. ¿De qué hablamos entonces cuando decimos que un problema social sufre un "proceso de configuración de su carácter público" y qué implicancias tiene esto en el estudio de ciertos casos y escándalos?

Algunos autores realizan una distinción sosteniendo que "lo público” reenvía a contextos diversos según se lo considere como adjetivo o 
como sustantivo. Mientras que como adjetivo, resulta ligado a la experiencia y la actividad consolidada a lo largo del tiempo en los regímenes democráticos, como sustantivo aparece más cercano a la idea de una "persona colectiva” con capacidades de auto-gobierno, de deliberación o participación, o bien, con competencias para la recepción mediática o cultural (Cefaï y Pasquier, 2003)

En el primer caso, el carácter público de un problema, está vinculado a las condiciones políticas que lo hacen posible. Como sostiene D. Cefaï (1996) su devenir público no puede reducirse a la mera posibilidad de observarlo o de describirlo sino que tiene que ver con una forma de institución inherente al régimen democrático. Esas condiciones de posibilidad se relacionan con los usos prácticos y discursivos que se han ido instituyendo con la invención de los regímenes democráticos y que incluyen tanto las actividades de denuncia, de reivindicación, de justificación que invocan el interés general que las legitima, cuanto los principios de justicia, de derecho, de igualdad en los que se apoyan y los procedimientos de argumentación, indagación y crítica, entre otros (Ibid).

En el segundo caso (el o los públicos) hay todo un campo de estudio centrado en distintos aspectos de la cuestión. Entre otras posibilidades, se analiza la conformación de públicos entendidos como "audiencias” (no sólo mediáticas sino también políticas, ciudadanas), la “opinión pública” en sus múltiples vías de conceptualización y abordaje o las movilizaciones sociales en tanto acciones colectivas que se desarrollan en el espacio público.

Si ambas posibilidades están presentes en el estudio de problemas públicos y de los acontecimientos considerados “casos resonantes” que pueden ser investigados, lo interesante del planteo de los autores franceses es que no dejan de lado un aspecto que ya hemos señalado anteriormente y que podríamos denominar “dimensión configurativa” del público y de lo público. Es decir, una dimensión relacionada con el devenir público, que como noción teórico-conceptual abre la posibilidad de analizar el proceso por el cual los problemas sociales (y los casos relacionados con ellos) adquieren el estatus de problemas públicos.

En principio, para estudiar el proceso de configuración del carácter público de un problema, hay que dilucidar qué tipo de fenómenos, considerados problemáticos, ganan la atención pública o son considerados de interés público cuando hay otros que no lo hacen y que permanecen en el ámbito de lo privado. Esa atención pública está asentada en la idea de que se trata de asuntos que conciernen a la generalidad del público, o a la mayoría, y cuya solución es pasible de ser llevada adelante por los poderes públicos, esto es, aquellos que tramitan el interés general por oposición al particular.

Desde una perspectiva, la atención pública puede ser considerada como recurso escaso, que desata una competencia entre distintos problemas y pone en carrera una serie de operaciones y estrategias que permitan a determinados actores controlarlo o poseerlo por el mayor tiempo posible. 
Lo que está en juego en esta carrera es, precisamente, el mantenimiento o el sostenimiento de su carácter público de manera prolongada (Cefaï, 1996; Hilgartner y Bosk, 1988). Entonces, en un sentido, el carácter público adquirido por un asunto está relacionado con estos procesos de puesta en visibilidad y de competencia por la atención, dado que se considera que es algo que afecta a la generalidad y se distingue así de problemas o asuntos personales o privados.

Ahora bien, el proceso de "adquisición de un carácter público” consiste en un conjunto de acciones que no son solamente dispositivos comunicacionales o de debate público. Esas acciones toman la forma de la "experiencia pública”, lo cual requiere acercarse a la manera en que los actores ponen en juego un sentido de la realidad y de la justicia; momentos de crisis o de transición son propicios para indagar esa dimensión (Cefaï y Pasquier, 2003).

Los casos o los escándalos, al constituir momentos disruptivos, constituyen buenas oportunidades para investigar el desarrollo de la experiencia pública, desarrollo ligado a la instauración de los agenciamientos de diversa índole (jurídicos, políticos, cívicos) que tienen lugar a través de esa experiencia y se erigen a la vez como limitaciones y como oportunidades (Ibid)

Las acciones públicas no corresponden sólo a los poderes públicos sino también a la acción colectiva de ciudadanos, grupos e instituciones que actúan en el espacio público y que se embarcan y comprometen en esa acción, en grados diversos y en distintos momentos en el escenario social. Desde ya que estas acciones deben encontrar un sustento de aceptación más o menos generalizada o mejor, de legitimidad. Lo hacen, en parte, apoyándose en el debate público o en la "opinión pública”.

La perspectiva desarrollada por Quéré (1997) postula, en tal sentido, que una sociología de la opinión pública debería principalmente, apoyarse en una "praxeología de la opinión". Ello involucra dos dimensiones principales. Por un lado, que gran parte de lo que la gente "opina” proviene menos de las discusiones entre sí, que de la incorporación de ciertos pensamientos, opiniones y juicios en acciones concretas. Es decir, la formación de la opinión y la validación intersubjetiva de lo que se dice y se hace se sustenta más bien en esta "economía de lo verosímil” (économie du vraisemblable), que en verdades racionales del tipo de aquellas producidas por la ciencia. Por otro lado, analizar la opinión no requiere tanto describir estados mentales, actitudes subjetivas o disposiciones psicológicas, sino indagar actividades u operaciones mediadas por recursos públicos tales como símbolos, conceptos, prácticas comunes, juegos de lenguaje, instituciones, usos, métodos, etc. (Ibid).

La opinión pública así concebida hace evidente una postura teórica acerca de cómo la acción atraviesa todas las dimensiones de estudio de "lo público" como tal. En la opinión hay ya un "sentido encarnado" que no es 
solamente retórico, sino que se manifiesta en un conjunto de operaciones prácticas puestas en marcha en los acontecimientos o los casos.

Uno de los aspectos centrales del proceso de configuración del carácter público de ciertos casos resonantes, es, como veremos, la movilización de públicos. En esa movilización no sólo hay acción a través de la conformación de opiniones consideradas válidas, sino que también hay una acción colectiva en el espacio público conformada por repertorios de diversa índole. En otras palabras, la constitución de públicos no se da solamente en tanto audiencias mediáticas ni agenciamientos en el campo jurídico, por ejemplo, sino que también existe una dimensión de acción colectiva propiamente dicha (repertorios de acción, conformación identitaria, movilización de recursos, procesos de “enmarcamiento”, etc.)

La denuncia, que como hemos visto se encuentra en la base de la conformación de los problemas públicos (y sobre todo de los casos y escándalos) encuentra varios frentes de expresión: en esta conformación de opiniones, confrontación de ideas y categorizaciones para definir lo sucedido, pero también en aquella organización y despliegue de acciones colectivas en el espacio público.

\section{La actividad de denuncia}

Si bien las teorías de los movimientos sociales constituyen un consolidado campo de estudio y ofrecen herramientas analíticas consistentes para abordar esos fenómenos, no debe confundirse la indagación de las movilizaciones suscitadas en el marco de un caso, con la exploración específica y pormenorizada de la lógica de la acción colectiva o de los movimientos sociales. Sin embargo, algunas nociones conceptuales ofrecidas por ese corpus teórico pueden resultar apropiadas para estudiar problemas públicos.

En realidad de lo que se trata, es de centrarse en la actividad de denuncia llevada adelante por ciertos actores, la cual puede tener lugar a través de una movilización, protesta, etc. o a través de otras estrategias o acciones para reclamar en el espacio público o ante los poderes públicos. En cualquier caso, existe siempre un conjunto de demandas y de demandantes que constituyen la médula de la indagación en el campo de estudio de los problemas públicos y de los casos y escándalos que puedan ser estudiados.

Como parte del proceso de adquisición de un carácter público, demandas y demandantes tienen su especificidad en el marco de cada problema público y de los casos que suelen aparecer vinculados a él. Numerosos analistas identifican en sus trabajos la centralidad de estos grupos o individuos y de sus actividades, sin dejar de prestar atención a las categorías (clasificaciones, descripciones, definiciones, etc.) utilizadas para llevar adelante las denuncias sobre determinadas situaciones o contextos en pos de su problematización pública. 
Lo relevante en este proceso de constitución de las demandas es su credibilidad, más que la verdad de las mismas (Loseke, 2003). Esta actividad de denuncia es conflictiva, pues es precisamente la credibilidad lo que está en juego entre los grupos que se constituyen en torno a los "affaires". Tal como señala Loseke (2003) existe una suerte de "jerarquía de la credibilidad" entre los demandantes, dado que las evaluaciones realizadas por algunos miembros de la audiencia, pueden resultar más importantes que otras. La resultante de ello es que algunos problemas no tengan tantas chances de ser considerados como tales, debido a que son llevados adelante por figuras sin demasiada credibilidad.

Otros analistas han considerado la actividad de demanda haciendo notar, por un lado, la importancia que adquiere la "propiedad" (ownership) del problema por parte de ciertos demandantes y por el otro, el proceso (y las prácticas) de "enmarcamiento" o la conformación de marcos en la acción colectiva ligada a determinados problemas públicos. Revisemos ambas cuestiones.

La noción de "propiedad" de un problema, trabajada por Gusfield (1981), es retomada también por otros autores (Best, 1999; Néveu, 2000) cuando se concentran en estudiar las interacciones o vinculaciones que pueden existir entre demandantes diversos, las estrategias que éstos utilizan o intentan utilizar para ampliar el campo de sus demandas o extender determinado reclamo.

Los “responsables de los movimientos sociales", buscan utilizar otras estrategias además de la movilización y esto puede darse bajo distintas modalidades, como la creación de acontecimientos o mensajes acordes a la voluntad de los medios de comunicación o a la búsqueda de relevancia. Pero el complemento más eficaz, como señala Néveu (2000), sigue siendo introducirse en las negociaciones con las autoridades y penetrar en el círculo de los "propietarios" de los problemas públicos. Aquellos que asumen la "propiedad" de los problemas, se convierten en la "palabra autorizada" acerca de los mismos, siendo frecuentemente consultados al respecto por medios, funcionarios públicos y otros actores. Los "propietarios" son las figuras que enmarcan o definen la orientación apropiada del problema, explicando de qué tipo de problema se trata. En cierta medida, podría decirse que tienen una buena cuota de responsabilidad en la estabilización de una definición del problema.

Por otra parte, la actividad de los demandantes incluye también una dimensión de "enmarcamiento" que es explicada por los analistas de problemas públicos, apoyándose en ciertos enfoques provenientes de las teorías de los movimientos sociales. Es reconocido cierto solapamiento entre los campos teóricos de la sociología de los problemas públicos y el estudio de los movimientos sociales, en el sentido en que el "enmarcamiento" bien puede asimilarse a las operaciones de configuración de la orientación de determinado problema por parte de los demandantes. 
Las “operaciones de enmarcamiento" no deben ser consideradas como motivaciones íntimas o visiones subjetivas de los actores, previamente existentes y orientativas de la acción. No denotan "estados de consciencia” sino "estados de hecho", maneras de "rendir cuentas" a los públicos. Son también formas de producir lo colectivo, formular causas públicas y montar problemas públicos (Cefaï, 2001).

Lo que queremos destacar aquí, es que el proceso que lleva a construir una respuesta de determinado tipo en el marco de un problema (por ejemplo, presentación de una organización social ante la justicia como parte afectada) demuestra que el "enmarcamiento" de un problema (o de los casos o escándalos que están en el origen de la actividad de denuncia) se produce a través de sentidos encarnados en operaciones prácticas y no solamente a través de categorías retóricas o narrativas. Esa respuesta concreta, por lo demás, va acumulando distintos tipos de denuncia (en el ejemplo anterior, puede sumar a la denuncia social o la mediática un canal de denuncia de otra índole como el judicial) y puede significar la posibilidad de interactuar con un conjunto de actores por fuera de las habituales referencias institucionales, políticas o profesionales, amplificando o profundizando la denuncia inicialmente enmarcada en un sentido, para ir adoptando progresivamente otras perspectivas, modos de actuar y categorizaciones que van modificando el problema público en cuestión.

En este punto, es preciso señalar algunas críticas que se le han formulado al enfoque del marco (frame analysis), sobre todo en lo que respecta a la relación entre actividad de "enmarcamiento" y constitución de problemas públicos.

En realidad lo que se ha pretendido señalar, ha sido cierta tendencia a considerar los problemas públicos como un trabajo coherente y racional de construcción, sobreestimando el carácter racional de la actividad de denuncia y subestimando en gran medida, las incertidumbres y los desacuerdos inherentes a toda movilización, así como a las condiciones en las que ésta se apoya (Trom y Zimmermann, 2001). Por otra parte, la disponibilidad de un problema público no garantiza de manera mecánica una exitosa actividad de movilización social.

Los autores citados definen a un problema público como un modo compartido, más o menos estable, de tematizar una situación percibida como problemática, a través de categorizaciones de personas, de actos, de acontecimientos, comprometiendo dicho proceso un conjunto heterogéneo de actores, situados en contextos históricos específicos. Los marcos de la movilización, por su parte, designan las múltiples maneras en las que, a través de la acción, se va confeccionando ese problema público y sus categorías, y en las que éste es sometido a críticas, modificaciones y desplazamientos. De esta manera, aparece un aspecto dinámico del concepto, mediante la idea de que los marcos tanto reenvían a condiciones preliminares del proceso de "enmarcamiento", como a su propio producto; así, éste va a condicionar ulteriores movilizaciones (Ibid: 283) ${ }^{10}$. 
Veamos ahora de qué modo una o varias definiciones y categorizaciones encuentran un lugar socialmente preponderante, contribuyendo así al proceso que se ha llamado “estabilización” de un problema público como tal.

\section{La politización del problema como parte de su proceso de estabilización}

La idea de la estabilización involucra la fijación de ciertos parámetros que funcionan como los límites concretos dentro de los cuales un problema público adquiere consistencia. En el proceso de estabilización de un problema público como tal, resultan más claras sus fronteras de exclusión respecto de otras definiciones o categorizaciones del problema.

Como hemos visto ya respecto del acontecimiento, algunos autores vinculan la estabilización o normalización del mismo a una reducción de su contingencia, esto es, de la multiplicidad de descripciones posibles para un mismo evento.

La pregunta que formula Barthélémy (1992) en este sentido, es cómo se fija el cierre operacional de una descripción, cómo se fija una perspectiva que da estabilidad al acontecimiento. La respuesta es que esto ocurre, por ejemplo, ligando un acontecimiento a un campo práctico, es decir, vinculándolo a la capacidad de actuar y de afectar, determinar sus agentes, de definir condiciones y consecuencias, de establecer responsabilidades. Ese conjunto de operaciones son las que hacen posible estabilizarlo o normalizarlo (Ibid)

En la literatura sobre procesos de constitución de problemas públicos, la estabilización es el procedimiento por el cual la evidencia acerca de determinados hechos es aportada por parte de ciertos actores, lo cual contribuye a validar los argumentos de las partes involucradas o enfrentadas en la disputa por identificar el problema de una manera y no de otra. Este procedimiento de validación se produce a partir de la intervención de determinadas voces autorizadas (expertos, técnicos, funcionarios, juristas) que proveen de categorías válidas para ayudar a dirimir las controversias. Cefaï (1996) por su parte, habla de la "institucionalización” de las arenas públicas cuando se constituyen actores colectivos y cuando sus discursos encuentran resonancia en las agencias administrativas y en los poderes públicos, cuando se han establecido mecanismos de confrontación y de negociación y se han rutinizado las operaciones de categorización (Ibid).

La intervención de los poderes públicos es esencial, puesto que éstos otorgan credenciales de "seriedad" al problema o la cuestión y a las reivindicaciones que le están asociadas. Éstas son alentadas a reformularse en un lenguaje acorde a los ámbitos administrativos, las instancias judiciales, las comisiones parlamentarias, etc. Por otra parte, esta fase de 
institucionalización o estabilización, no exime de la dimensión conflictiva o polémica, propia de la constitución de un problema público (Ibid).

Resulta importante explorar el modo en que ciertas categorizaciones utilizadas para definir lo sucedido, encuentran eco en el poder político y son recuperadas no sólo para diseñar y poner en marcha medidas políticas y/o jurídicas, sino para confrontar políticamente contando con un antecedente de legitimidad social que apuntale la contienda entre actores de poder desigual.

De manera más acotada, entonces, haremos hincapié en la estabilización del problema pero centrándonos en el proceso de “politización”. En general, la politización aparece relacionada con la repercusión de los casos en el escenario político. Esa repercusión, aunque en los momentos iniciales aparece más "pegada” al caso particular, es decir, aparece relacionada en un sentido literal con el mismo, pareciera ir generando progresivamente debates e impulsando medidas acerca de cuestiones de carácter político y social de índole más universal.

Determinados casos resonantes facilitan además la instalación de ciertos temas en la agenda política, cuyos indicadores más salientes son la inclusión de esas temáticas en debates parlamentarios, debates partidarios o tomas de posición del poder político al respecto ${ }^{11}$. Con relación al ámbito de las políticas públicas y al ámbito legislativo y judicial, las últimas décadas en la Argentina, han sido testigos de la implementación de políticas estatales y de legislación, vinculadas con la temática relacionada con los casos particulares o la modificación en algún sentido de las previamente existentes ${ }^{12}$.

Por otra parte, también es importante prestar atención al modo en que son presentadas las medidas políticas relacionadas con un caso particular. Más arriba hacíamos referencia al proceso por el cual, al inicio esas medidas aparecen estrechamente ligadas a un acontecimiento particular, devenido caso resonante y luego van ganando universalidad al ser reconocidas como parte de una demanda social relacionada al bienestar común o al interés general. En el marco del estudio de los problemas públicos y de los casos, debe practicarse sobre ese proceso una indagación específica y pormenorizada dado que, en parte, es allí donde se juega la estabilización de un problema, la "fijación de su significado" en términos de su pasaje a erigirse en "cosa pública". No es entonces inocente ni neutral el modo en que el poder político o los poderes públicos hacen aparecer las medidas políticas relacionadas con un caso, ni cuáles son las voces autorizadas o los argumentos considerados legítimos para sostener determinadas líneas de acción.

\section{Las narraciones}

Los estudios empíricos sobre problemas públicos han mostrado el papel central que juegan las narraciones (y los modos de narrar) en dotar de legitimidad a un determinado problema y cómo esas narraciones, en tanto 
pequeñas historias o relatos acerca del fenómeno, constituyen procedimientos que contribuyen a legitimarlo. Los relatos ayudan a otorgar un orden coherente a un conjunto de sucesos, acciones y sujetos mediante el establecimiento de secuencias cronológicas, presentación de personajes y argumentos e identificación de consecuencias y desenlaces. A menudo esas historias son relatos morales que atribuyen responsabilidades señalando divisiones entre víctimas y victimarios, propiciando tomas de posición e ideas acerca de aquello que "debería hacerse al respecto".

$\mathrm{Al}$ investigar casos paradigmáticos, resulta fundamental desentrañar el proceso por el cual estos relatos se han convertido en piezas estables y legítimas para narrar dichos fenómenos, han confrontado con éxito con otros modos de narrar y han devenido elementos bastante naturalizados al describir o valorar determinada situación. En otras palabras, la tarea del investigador es dejar al descubierto las marcas del proceso de construcción social de dichos relatos, antes de que se conviertan en el modo legítimo y estabilizado de presentar el caso. Como ha sido señalado por algunos autores, los relatos son recursos presentes en la mayoría de las casuísticas jurídicas, morales, religiosas. En la medida en que nos interesa desentrañar la relación entre casos y problemas públicos, los relatos juegan un papel importante en tal sentido: sirven para exponer una situación, para hacer comprender cómo se ha llegado a ella al punto de constituirse en un problema. Para Revel y Passeron (2005), un caso es el producto de una historia y resulta secundario que tal historia sea real o ficticia, aunque sí es decisivo que pueda dar cuenta del proceso y de las circunstancias que califican al caso. Esto no significa que no haya una dimensión "verdadera” en el caso, sino que no es la experiencia temporal aquello con lo que éste se identifica. El caso no reproduce una historia, sino que a través de operaciones de selección, reorganización e incluso estilización de ciertos datos, la produce.

Algunos analistas sugieren que una perspectiva basada en un "enfoque dramático" ofrece un medio para estudiar determinado tipo de acciones sociales: aquellas que conciernen específicamente a las acciones simbólicas de la vida pública y al tipo de entidades públicas a las cuales éstas otorgan consistencia (Barthélémy, 1992). Es decir, en el marco de un caso hay una puesta en escena llevada adelante por los actores, que se juega en la escena pública, delante de una audiencia. Ese "public drama” (Gusfield, 1981) no puede prescindir del entramado de convenciones y reglas cuyos códigos son socialmente conocidos; es en función de esa trama que actores, público y todos los que juegan algún papel como "voces autorizadas", contribuyen a volver públicamente inteligible aquello que transcurre a la "vista de todos” (Barthélémy, 1992)

En el proceso de "legitimación” de un problema público, un relato (como parte de una narración) y una dramatización ("mise en scène") han resultado predominantes y creíbles para definirlo. Más allá de esa "puesta en relato" que incluye por cierto, determinadas representaciones sociales, existen imágenes asociadas al caso que también constituyen formas en mayor o en menor medida legitimadas de representarlo y que no son sólo de natu- 
raleza retórica. Desde nuestra perspectiva, esas imágenes forman parte de un conjunto de materiales culturales de distinta índole (fotografías, videos, panfletos, libros, consignas) cuya relación con el "relato legítimo" debe ser explorada, si lo que queremos es ampliar el estudio de la base de sustentación simbólica de la conformación de un caso como paradigmático. Así, se vuelve importante indagar de qué manera los mecanismos que operan para otorgar significados socialmente legítimos a un problema público, incorporan estas imágenes visuales, iconográficas, relatos ficcionales y otras formas culturales de representación de la realidad, a la construcción de un relato sobre los casos que son asociados a dicho problema. Y sobre todo, cómo esa manera de incorporar este conjunto de imágenes puede llegar a tener algún tipo de vínculo con la legitimidad alcanzada por el relato estable o estabilizado de ese problema, en la medida en que los grupos o los actores que participan en la disputa por el sentido, los vuelven parte del mismo.

\section{Consideraciones finales}

Estudiar un problema público exige estar atentos a un conjunto de dimensiones analíticas relacionadas, como hemos visto, con procesos de denuncia pública, medidas políticas y categorizaciones ofrecidas al respecto por una amplia variedad de actores sociales y políticos, entre otros aspectos. Los casos resonantes que, en ese marco de experiencia pública, son asociados con determinado problema en un momento y un lugar dados (por ejemplo, la cuestión de la impunidad o la "inseguridad" en la Argentina contemporánea) no son meros acontecimientos particulares que ilustran una situación general ya problematizada. Los casos pueden ser sumamente reveladores de los procesos de denuncia pública y de movilización social que suelen producirse en torno a ellos, permitiendo estudiar a través de esos acontecimientos, qué marcos de interpretación están operando en dichos procesos, si éstos forman parte de un problema público y qué nuevas o renovadas formas de concebirlo y narrarlo pueden tener lugar de allí en más. 


\section{Notas}

* Algunos contenidos de este artículo forman parte de uno de los capítulos de la tesis doctoral de la autora, actualmente en elaboración. Doctorado en Ciencias Sociales, Universidad Nacional de Gral. Sarmiento (UNGS)-Instituto de Desarrollo Económico y Social (IDES)

${ }^{1}$ Esta distinción permite además, considerar otra cuestión central como es la relación entre la responsabilidad causal y la responsabilidad política, en la medida en que ciertos cambios en las categorizaciones cognitivas o en las definiciones causales, tienen consecuencias en las instituciones que deben tramitar dichos problemas así definidos (Gusfield, 1981: 6).

${ }^{2}$ Sobre la noción de “arena pública” véase Gusfield (1981) y también Cefai (2006)

${ }^{3}$ En base a un caso estudiado en conjunto con L. Quéré, el “affaire Carpentras”, el autor ejemplifica este punto con la diferencia en la acción pública suscitada a raíz del acontecimiento de la profanación de ese cementerio israelita en 1990, en Francia. Mientras que en un primer momento la descripción del mismo como "profanación" tuvo determinadas implicancias prácticas, su posterior consideración como "acto antisemita”, significó la ampliación de ese campo práctico, abriendo el espectro de involucrados, víctimas, responsabilidades atribuidas y, en general, el modo en que el público se consideró "afectado" por lo sucedido (Barthélémy, 1992: 134-135).

${ }^{4}$ Thompson ubica cinco características del escándalo en su uso corriente: 1) transgresión o contravención de ciertos valores, normas o códigos morales, 2) las acciones o acontecimientos implican cierto grado de secreto u ocultación que, no obstante, llegan a ser conocidos por terceros, 3) algunos no participantes desaprueban las acciones y pueden sentirse ofendidos por la transgresión, 4) éstos expresan su desaprobación denunciando públicamente las acciones o los acontecimientos, 5) la revelación de las acciones o los acontecimientos pueden dañar la reputación de los individuos responsables (Thompson, 2001: 32)

${ }^{5}$ Aquí los autores subrayan los aportes de la tradición antropológica al estudio de los escándalos, y en particular aquellos de M. Gluckman, que los considera como una de las principales actividades a través de la cual los grupos se rediseñan, se modifican las jerarquías, se instituyen pertenencias. En este sentido también apuntan, que analizar esta "dimensión instituyente” obliga a una sociología particularmente dinámica, que no se contenta con deducir el acontecimiento de la estructura e interpretar ex post lo que adviene como aquello que “debía suceder”, sino que se orienta a considerar en qué medida todo escándalo produce un estado de la organización social que no es completamente preexistente ni enteramente previsible (De Blic y Lemieux, 2005: 12).

${ }^{6}$ Tanto en el campo de estudio de los problemas públicos, como en las perspectivas que abordan el escándalo como objeto de estudio "à part entière”, los actores adquieren agencia en el proceso mismo de la confrontación de posturas, discursos y prácticas y no son entidades preexistentes a sus acciones públicas. Véase Cefaï (1996) y De Blic y Lemieux (2005)

${ }^{7}$ Desde un punto de vista estrictamente metodológico, para un observador no hay ninguna posibilidad de describir un escándalo si no existe un público (por mínimo que sea) que se ha constituido para hacer notar una transgresión y denunciarla (De Blic y Lemieux, 2005: 15)

${ }^{8}$ Considerar un escándalo como “prueba” significa que éste permite a la comunidad 
involucrada, determinar si los valores transgredidos le son o no indiferentes, pero también implica reconocer la reversibilidad potencial de las relaciones de dominación que abre toda denuncia pública de una transgresión, aunque ese momento pueda volver a clausurarse rápidamente (De Blic y Lemieux, 2005:13)

${ }^{9}$ Es por ello que el escándalo y el affaire jamás ponen fin a los "comentarios o rumores". Por el contrario, las modalidades denunciativas "oficiosas" continúan a menudo bien activas al margen de la escena pública en la que se juegan las acusaciones “oficiales” (De Blic y Lemieux, 2005: 27)

${ }^{10} \mathrm{D}$. Trom subraya que sin la disponibilidad previa de marcos de percepción y de categorización, los actores estarían desprovistos para convertir las dificultades experimentadas en la vida cotidiana en problemas públicos claramente identificables por la opinión pública, capaces de ser sujetos de la acción pública (Cefaï y Trom, 2001: 17).

${ }^{11}$ En tal sentido, y entre otros muchos casos, algunas muertes violentas erigidas en "casos resonantes” o escándalos políticos en la Argentina, consiguieron una gran repercusión en el escenario político en diferentes niveles. Podemos mencionar así los casos de María Soledad Morales (1990), Omar Carrasco (1994), José Luis Cabezas (1997) y Axel Blumberg (2004).

${ }^{12}$ Los ejemplos más ilustrativos de este punto en la Argentina de las últimas décadas son, entre otros: la reforma penal de 1998 (caso Cabezas), la ley de abolición del servicio militar obligatorio (caso Carrasco), el paquete de leyes penales sancionado en el año 2004 (caso Blumberg). 


\section{Bibliografía}

Barthélémy, M. (1992), “Événement et espace public: l’affaire Carpentras”, en Quaderni, $n^{\circ} 18$, Automne, Paris.

Best, J. (1999), Random Violence. How we talk about new crimes and new victims, Los Angeles, University of California Press, Los Angeles.

Blumer, H. (1971), “Social problems as collective behavior”, Social Problems, $n^{\circ} 18$ (3) Dispoinible en: http://www.persee.fr.

Boltanski, L., E. Claverie, N. Offenstadt, y Van Damme, S. (2007) (dir.), Affaires, scandales et grandes causes. De Socrate à Pinochet, Stock, Paris.

Cefaï, D. (1996), “La construction des problèmes publics. Définitions de situations dans des arènes publiques”, Réseaux, vol. $14 n^{\circ} 75$, Paris.

Cefaï, D. et D. Pasquier, dir. (2003), Les sens du public. Publics politiques, publics médiatiques, PUF, Paris.

Cefaï, D.y D. Trom (2001), Les formes de l'action collective. Mobilisations dans des arenes publiques, EHESS, Paris.

Champagne, P. (1984), “La manifestation. La production de l'évenément politique”, Actes de la Récherche en Sciences Sociales, vol. 52, $n^{\circ} 1$, EHSS, Paris.

Clavérie, E. (1994), “Proces, affaire, cause. Voltaire et l'innovation critique”, en Politix, Révue des Sciences Sociales du Politique, $n^{\circ} 26$, vol. 7, Universidad de París, Paris.

De Blic, D. y Lemieux, C. (2005), “Le scandale comme épreuve. Éléments de sociologie pragmatique”, Politix, Révue des Sciences Sociales du Politique $n^{\circ} 71$, vol. 18, Universidad de París, Paris.

França, V. y Almeida, R. (2008), “O acontecimento e seus públicos: um estudo de caso”, en Contemporanea, vol. 6, n², Salvador de Bahía

Gusfield, J. (1981), The Culture of Public Problems: Drinking-Driving and the Symbolic Order, University of Chicago Press, Chicago.

Hilgartner S. y Bosk, Ch. (1988), “The Rise and Fall of Social Problems: A Public Arenas Model”, en The American Journal of Sociology, vol. 94, $N^{\circ} 1$, The University Chicago Press, Chicago.

Loseke, D. (2003), Thinking about social problems, Aldine de Gruyter, New York.

Néveu, É. (2000), Sociología de los movimientos sociales, Editorial ABYAYALA, Quito. 
Néveu, E. y Quéré, L. (1997), “The age of events. The spume of history or an information master-frame?” en Réseaux, vol. $5 n^{\circ} 1$, Disponible en : http://www.persee.fr/web/revues/home/prescript/article/reso_09699864_1997_num_5_1_3320

Nora, P. (1972), “L’événement monstre” Communications, vol. 18, $N^{\circ} 1$, Paris

Quéré, L. (1997), “L’opinion : l’économie du vraisemblable. Introduction à une approche praxéologique de l'opinion publique”, en Sociologie de la communication, vol. $1, n^{\circ} 1$, Reseux Reader-CNET, Paris.

Snow, D. (2001), “Analyse des cadres et mouvements sociaux” en Cefaï, D. y Trom, D. Les formes de l'action collective. Mobilisations dans des arenes publiques, EHESS, Paris.

Thompson, J. (2001), Escándalo político: poder y visibilidad en la era de los medios de comunicación, Paidós Ibérica, Barcelona.

Idem (2005), “The New Visibility”, en Theory, Culture, Society, $n^{\circ} 22$, Stanford University Press, Stanford.

Trom, D. y Zimmermann, B. (2001), “Cadres et institution des problemes publics” en Cefaï, D.y D. Trom Les formes de l'action collective. Mobilisations dans des arenes publiques, EHESS, Paris.

Verón, E. (1983), Construir el acontecimiento, Gedisa, Barcelona.

Recibido: 02.05.2011

Aceptado: 23.11.2011 